\title{
BMJ Open Impact of the COVID-19 pandemic on mental health and well-being of communities: an exploratory qualitative study protocol
}

\author{
Anam Shahil Feroz (D) , ${ }^{1,2}$ Naureen Akber Ali, ${ }^{3}$ Noshaba Akber Ali, ${ }^{1}$ Ridah Feroz, ${ }^{4}$ \\ Salima Nazim Meghani, ${ }^{1}$ Sarah Saleem ${ }^{1}$
}

To cite: Shahil Feroz A, Akber Ali N, Akber Ali N, et al. Impact of the COVID-19 pandemic on mental health and well-being of communities: an exploratory qualitative study protocol. BMJ Open 2020;10:e041641. doi:10.1136/ bmjopen-2020-041641

- Prepublication history and additional material for this paper are available online. To view these files, please visit the journal online ().

ASF and NAA are joint first authors.

Received 16 June 2020 Revised 02 November 2020 Accepted 06 December 2020

\section{Check for updates}

(c) Author(s) (or their employer(s)) 2020. Re-use permitted under CC BY-NC. No commercial re-use. See rights and permissions. Published by BMJ.

${ }^{1}$ Community Health Sciences, Aga Khan University, Karachi, Pakistan

${ }^{2}$ Institute of Health Policy, Management and Evaluation, University of Toronto, Toronto, Ontario, Canada

${ }^{3}$ School of Nursing and Midwifery, Aga Khan University, Karachi, Pakistan

${ }^{4}$ Aga Khan University Institute for Educational Development, Karachi, Pakistan

Correspondence to Ms Anam Shahil Feroz; anam.sahyl@gmail.com

\section{ABSTRACT}

Introduction The COVID-19 pandemic has certainly resulted in an increased level of anxiety and fear in communities in terms of disease management and infection spread. Due to fear and social stigma linked with COVID-19, many individuals in the community hide their disease and do not access healthcare facilities in a timely manner. In addition, with the widespread use of social media, rumours, myths and inaccurate information about the virus are spreading rapidly, leading to intensified irritability, fearfulness, insomnia, oppositional behaviours and somatic complaints. Considering the relevance of all these factors, we aim to explore the perceptions and attitudes of community members towards COVID-19 and its impact on their daily lives and mental well-being. Methods and analysis This formative research will employ an exploratory qualitative research design using semistructured interviews and a purposive sampling approach. The data collection methods for this formative research will include indepth interviews with community members. The study will be conducted in the Karimabad Federal B Area and in the Garden (East and West) community settings in Karachi, Pakistan. The community members of these areas have been selected purposively for the interview. Study data will be analysed thematically using NVivo V.12 Plus software.

Ethics and dissemination Ethical approval for this study has been obtained from the Aga Khan University Ethical Review Committee (2020-4825-10599). The results of the study will be disseminated to the scientific community and to the research subjects participating in the study. The findings will help us explore the perceptions and attitudes of different community members towards the COVID-19 pandemic and its impact on their daily lives and mental well-being.

\section{BACKGROUND}

The COVID-19 pandemic has affected almost 180 countries since it was first detected in Wuhan, China in December 2019. ${ }^{2}$ The COVID-19 outbreak has been declared a public health emergency of international concern by the WHO. ${ }^{3}$ The WHO estimates the global mortality to be about $3.4 \%{ }^{4}$;
Strengths and limitations of this study

- The mental health impact of the COVID-19 pandemic is likely to last much longer than the physical health impact, and this study is positioned well to explore the perceptions and attitudes of community members towards the pandemic and its impact on their daily lives and mental well-being.

- This study will guide the development of contextspecific innovative mental health programmes to support communities in the future.

- One limitation is that to minimise the risk of infection all study respondents will be interviewed online over Zoom and hence the authors will not have the opportunity to build rapport with the respondents or obtain non-verbal cues during interviews.

however, death rates vary between countries and across age groups. ${ }^{5}$ In Pakistan, a total of 10880 cases and 228 deaths due to COVID-19 infection have been reported to date. ${ }^{6}$

The worldwide COVID-19 pandemic has not only incurred massive challenges to the global supply chains and healthcare systems but also has a detrimental effect on the overall health of individuals. ${ }^{7}$ The pandemic has led to lockdowns and has created destructive impact on the societies at large. Most company employees, including daily wage workers, have been prohibited from going to their workplaces or have been asked to work from home, which has caused jobrelated insecurities and financial crises in the communities. $^{8}$ Educational institutions and training centres have also been closed, which resulted in children losing their routine of going to schools, studying and socialising with their peers. Delay in examinations is likewise a huge stressor for students. ${ }^{8}$ Alongside this, parents have been struggling with creating a structured milieu for their children. ${ }^{9}$ COVID-19 has hindered the normal 
routine life of every individual, be it children, teenagers, adults or the elderly. The crisis is engendering burden throughout populations and communities, particularly in developing countries such as Pakistan which face major challenges due to fragile healthcare systems and poor economic structures. ${ }^{10}$

The COVID-19 pandemic has certainly resulted in an increased level of anxiety and fear in communities in terms of disease management and infection spread. ${ }^{8}$ Further, the highly contagious nature of COVID-19 has also escalated confusion, fear and panic among community residents. Moreover, social distancing is often an unpleasant experience for community members and for patients as it adds to mental suffering, particularly in the local setting where get-togethers with friends and families are a major source of entertainment. ${ }^{9}$ Recent studies also showed that individuals who are following social distancing rules experience loneliness, causing a substantial level of distress in the form of anxiety, stress, anger, misperception and post-traumatic stress symptoms. ${ }^{8} 11$ Separation from family members, loss of autonomy, insecurity over disease status, inadequate supplies, inadequate information, financial loss, frustration, stigma and boredom are all major stressors that can create drastic impact on an individual's life. ${ }^{11}$ Due to fear and social stigma linked with COVID-19, many individuals in the community hide their disease and do not access healthcare facilities in a timely manner. ${ }^{12}$ With the widespread use of social media, ${ }^{13}$ rumours, myths and inaccurate information about COVID-19 are also spreading rapidly, not only among adults but are also carried on to children, leading to intensified irritability, fearfulness, insomnia, oppositional behaviours and somatic complaints. ${ }^{9}$ The psychological symptoms associated with COVID-19 at the community level are also manifested as anxiety-driven panic buying, resulting in exhaustion of resources from the market. ${ }^{14}$ Some level of panic also dwells in the community due to the unavailability of essential protective equipment, particularly masks and sanitisers. ${ }^{15}$ Similarly, mental health issues, including depression, anxiety, panic attacks, psychotic symptoms and even suicide, were reported during the early severe acute respiratory syndrome outbreak. ${ }^{16} 17$ COVID-19 is likely posing a similar risk throughout the world. ${ }^{12}$

The fear of transmitting the disease or a family member falling ill is a probable mental function of human nature, but at some point the psychological fear of the disease generates more anxiety than the disease itself. Therefore, mental health problems are likely to increase among community residents during an epidemic situation.
Considering the relevance of all these factors, we aim to explore the perceptions and attitudes towards COVID-19 among community residents and the impact of these perceptions and attitude on their daily lives and mental well-being.

\section{METHODS AND ANALYSIS \\ Study design}

This study will employ an exploratory qualitative research design using semistructured interviews and a purposive sampling approach. The data collection methods for this formative research will include indepth interviews (IDIs) with community members. The IDIs aim to explore perceptions of community members towards COVID-19 and its impact on their mental well-being.

\section{Study setting and study participants}

The study will be conducted in two communities in Karachi City: Karimabad Federal B Area Block 3 Gulberg Town, and Garden East and Garden West. Karimabad is a neighbourhood in the Karachi Central District of Karachi, Pakistan, situated in the south of Gulberg Town bordering Liaquatabad, Gharibabad and Federal B Area. The population of this neighbourhood is predominantly Ismailis. People living here belong mostly to the middle class to the lower middle class. It is also known for its wholesale market of sports goods and stationery. Garden is an upmarket neighbourhood in the Karachi South District of Karachi, Pakistan, subdivided into two neighbourhoods: Garden East and Garden West. It is the residential area around the Karachi Zoological Gardens; hence, it is popularly known as the 'Garden' area. The population of Garden used to be primarily Ismailis and Goan Catholics but has seen an increasing number of Memons, Pashtuns and Baloch. These areas have been selected purposively because the few members of these communities are already known to one of the coinvestigators. The coinvestigator will serve as a gatekeeper for providing entrance to the community for the purpose of this study. Adult community members of different ages and both genders will be interviewed from both sites, as mentioned in table 1. Interview participants will be selected following the eligibility criteria.

\section{IDIs with community members}

We will conduct IDIs with community members to explore the perceptions and attitudes of community members towards COVID-19 and its effects on their daily lives and mental well-being. IDI participants will be identified via

Table 1 Study participants for indepth interviews

Indepth interview participants

Young adults (18-35 years)

Middle-aged adults (36-55 years)

Older adults ( $>55$ years)

\section{Sample range}

6-8 (4 male and 4 female)

6-8 (4 male and 4 female)

6-8 (4 male and 4 female) 
the community WhatsApp group, and will be invited for an interview via a WhatsApp message or email. Consent will be taken over email or WhatsApp before the interview begins, where they will agree that the interview can be audio-recorded and that written notes can be taken. The interviews will be conducted either in Urdu or in English language, and each interview will last around 40-50 min. Study participants will be assured that their information will remain confidential and that no identifying features will be mentioned on the transcript. The major themes will include a general discussion about participants' knowledge and perceptions about the COVID-19 pandemic, perceptions on safety measures, and perceived challenges in the current situation and its impact on their mental well-being. We anticipate that 24-30 interviews will be conducted, but we will cease interviews once data saturation has been achieved. Data saturation is the point when no new themes emerge from the additional interviews. Data collection will occur concurrently with data analysis to determine data saturation point. The audio recordings will be transcribed by a transcriptionist within 24 hours of the interviews.

An interview guide for IDIs is shown in online supplemental annex 1 .

\section{Eligibility criteria}

The following are the criteria for inclusion and exclusion of study participants:

\section{Inclusion criteria}

- Residents of Garden (East and West) and Karimabad Federal B Area of Karachi who have not contracted the disease.

\section{Exclusion criteria}

- Those who refuse to participate in the study.

- Those who have experienced COVID-19 and are undergoing treatment.

- Those who are suspected for COVID-19 and have been isolated/quarantined.

- Family members of COVID-19-positive cases.

\section{Data collection procedure}

A semistructured interview guide has been developed for community members. The initial questions on the guide will help to explore participants' perceptions and attitudes towards COVID-19. Additional questions on the guide will assess the impact of these perceptions and attitude on the daily lives and mental health and well-being of community residents. All semistructured interviews will be conducted online via Zoom or WhatsApp. Interviews will be scheduled at the participant's convenient day and time. Interviews are anticipated to begin on 1 December 2020.

\section{Patient and public involvement}

No patients were involved.

\section{Data analysis}

We will transcribe and translate collected data into English language by listening to the audio recordings in order to conduct a thematic analysis. NVivo V.12 Plus software will be used to import, organise and explore data for analysis. Two independent researchers will read the transcripts at various times to develop familiarity and clarification with the data. We will employ an iterative process which will help us to label data and generate new categories to identify emergent themes. The recorded text will be divided into shortened units and labelled as a 'code' without losing the main essence of the research study. Subsequently, codes will be analysed and merged into comparable categories. Lastly, the same categories will be grouped into subthemes and final themes. To ensure inter-rater reliability, two independent investigators will perform the coding, category creation and thematic analyses. Discrepancies between the two investigators will be resolved through consensus meetings to reduce researcher bias.

\section{Ethics and dissemination}

Study participants will be asked to provide informed, written consent prior to participation in the study. The informed consent form can be submitted by the participant via WhatsApp or email. Participants who are unable to write their names will be asked to provide a thumbprint to symbolise their consent to participate. Ethical approval for this study has been obtained from the Aga Khan University Ethical Review Committee (2020-4825-10599). The study results will be disseminated to the scientific community and to the research subjects participating in the study. The findings will help us explore the perceptions and attitudes of different community members towards the COVID-19 pandemic and its impact on their daily lives and mental well-being.

\section{DISCUSSION}

The findings of this study will help us to explore the perceptions and attitudes towards the COVID-19 pandemic and its impact on the daily lives and mental well-being of individuals in the community. Besides, an indepth understanding of the needs of the community will be identified, which will help us develop contextspecific innovative mental health programmes to support communities in the future. The study will provide insights into how communities are managing their lives under such a difficult situation.

Contributors ASF and NAA conceived the study. ASF, NAA, RF, NA, SNM and SS contributed to the development of the study design and final protocols for sample selection and interviews. ASF and NAA contributed to writing the manuscript. All authors reviewed and approved the final version of the paper.

Funding The authors have not declared a specific grant for this research from any funding agency in the public, commercial or not-for-profit sectors.

Competing interests None declared.

Patient consent for publication Not required.

Provenance and peer review Not commissioned; externally peer reviewed

Supplemental material This content has been supplied by the author(s). It has not been vetted by BMJ Publishing Group Limited (BMJ) and may not have been peer-reviewed. Any opinions or recommendations discussed are solely those 
of the author(s) and are not endorsed by BMJ. BMJ disclaims all liability and responsibility arising from any reliance placed on the content. Where the content includes any translated material, BMJ does not warrant the accuracy and reliability of the translations (including but not limited to local regulations, clinical guidelines, terminology, drug names and drug dosages), and is not responsible for any error and/or omissions arising from translation and adaptation or otherwise.

Open access This is an open access article distributed in accordance with the Creative Commons Attribution Non Commercial (CC BY-NC 4.0) license, which permits others to distribute, remix, adapt, build upon this work non-commercially, and license their derivative works on different terms, provided the original work is properly cited, appropriate credit is given, any changes made indicated, and the use is non-commercial. See: http://creativecommons.org/licenses/by-nc/4.0/.

\section{ORCID iD}

Anam Shahil Feroz http://orcid.org/0000-0003-0180-0213

\section{REFERENCES}

1 Heymann DL. Data sharing and outbreaks: best practice exemplified. Lancet 2020;395:469-70.

2 Vara V. Coronavirus outbreak: the countries affected. Available: https://www.pharmaceutical-technology.com/features/coronavirusoutbreak-the-countries-affected/ [Accessed 16 April 2020].

3 World Health Organization. Mental health and psychosocial considerations during the COVID-19 outbreak. World Health Organization, 2020.

4 WHO. Coronavirus disease 2019 (COVID-19) situation report 46, 2020b. Available: https://www.who.int/docs/default-source/ coronaviruse/situation-reports/20200306-sitrep-46-COVID-19.pdf? sfvrsn=96b04adf_2

5 Baud D, Qi X, Nielsen-Saines K, et al. Real estimates of mortality following COVID-19 infection. Lancet Infect Dis 2020;20:773.
6 Worldometer. COVID-19 coronavirus pandemic. Available: https:// www.worldometers.info/coronavirus/coronavirus-death-rate/ [Accessed April 22, 2020].

7 Ebrahim SH, Ahmed QA, Gozzer E, et al. Covid-19 and community mitigation strategies in a pandemic. BMJ 2020:m1066.

8 Zhou X, Snoswell CL, Harding LE, et al. The role of telehealth in reducing the mental health burden from COVID-19. Telemed J E Health 2020;26:377-9.

9 Nargis Asad. Simple ways to be Resilient in pandemic times. Available: https://tribune.com.pk/story/2200498/6-simple-waysresilient-pandemic-times/ [Accessed 18 April, 2020].

10 van Weel C, Kassai R, Qidwai W, et al. Primary healthcare policy implementation in South Asia. BMJ Glob Health 2016;1:e000057.

11 Brooks SK, Webster RK, Smith LE, et al. The psychological impact of quarantine and how to reduce it: rapid review of the evidence. The Lancet 2020;395:912-20.

12 Roy D, Tripathy S, Kar SK, et al. Study of knowledge, attitude, anxiety \& perceived mental healthcare need in Indian population during COVID-19 pandemic. Asian J Psychiatr 2020;51:102083.

13 Schwartz J, King C-C, Yen M-Y. Protecting Health Care Workers during the COVID-19 Coronavirus Outbreak-Lessons from Taiwan's SARS response. Clinical Infectious Diseases 2020.

14 Collett M. Coronavirus update: more COVID-19 cases confirmed across Australia as shoppers stock up on toilet paper. Groceries 2020 https://www.abc.net.au/news/2020-03-04/coronavirus-liveupdates-toiletpaper-panic-buyinglimits/12023040

15 WHO. Rolling updates on coronavirus disease (COVID-19), 2020c. Available: https://www.who.int/emergencies/diseases/novelcoronavirus-2019/events-as-they-happen

16 Liu T, Chen X, Miao G. Recommendations on diagnostic criteria and prevention of SARS-related mental disorders. J Clin Psychol Med 2003;13:188-91.

17 Maunder R, Hunter J, Vincent L. The immediate psychological and occupational impact of the 2003 SARS outbreak in a teaching hospital. CMAJ 2003;168:1245-51. 